\title{
Pressure wounds in a cohort of critical patients: incidence and associated factors
}

\author{
Lesão por pressão em uma coorte de pacientes críticos: incidência e fatores associados
}

Lesión por presión en pacientes críticos: incidencia y factores asociados

\author{
Alexandra Nogueira Mello Lopes ${ }^{\mathrm{a}}$ \\ Érica Batassinia \\ Mariur Gomes Beghetto ${ }^{b}$
}

\section{How to cite this article: \\ Lopes ANM, Batassini E, Beghetto MG. Pressure wounds in a cohort of critical patients: incidence and associated factors. Rev Gaúcha Enferm. 2021;42:e20200001. doi: https://doi.org/10.1590/1983- 1447.2021.20200001}

\footnotetext{
a Hospital de Clínicas de Porto Alegre (HCPA). Porto Alegre, Rio Grande do Sul, Brazil.

b Universidade Federal do Rio Grande do Sul (UFRGS), Escola de Enfermagem, Departamento de Assistência e Orientação Profissional. Porto Alegre, Rio Grande do Sul, Brazil.
}

\section{ABSTRACT}

Aim: To assess the incidence and factors associated with pressure wounds in patients of a Brazilian clinical and surgical Intensive Care Center (composed of three Intensive Care Units).

Method: Cohort monitored for clinical and therapeutic variables in an Intensive Care Center. Cox's Multiple Regression was employed, establishing the number of days until the first pressure injury as a time variable; the omnibus test was also performed.

Results: 178 patients, 64 (36\%) developed at least one pressure wound. The independent variables for the risk of pressure wounds were: Braden <13 (HR: 10.6; 95\% Cl: 2.5-43.7), history of previous stroke (HR: 2.6; 95\% Cl: 1.3-5.0), age > 60 years (HR: 2.0; 95\% Cl: 1.2-3.5), nothing by mouth time (HR: 1.06; 95\% Cl 1.02-1.10) and physical therapy days (HR: $0.81 ; 95 \%$ Cl: $0.73-0.91)$.

Conclusion: Pressure wounds were incident. Braden $<13$ points, history of previous strokes, being elderly, and time in nothing by mouth were shown to be independent risk factors for pressure wounds. The days of exposure to physical therapy were protective. These findings corroborate recommendations to monitor the frequency of pressure wounds and to establish protective measures based on local indicators. Keywords: Pressure ulcer. Critical care. Intensive care units.

\section{RESUMO}

Objetivo: Avaliar a incidência e fatores associados à Lesão por Pressão em pacientes de um Centro de Terapia Intensivo de um hospital universitário do Sul do Brasil.

Método: Coorte que acompanhou variáveis clínicas e terapêuticas em centro de terapia intensiva. Empregada Regressão Múltipla de Cox, na qual estabeleceu-se o número de dias até a primeira lesão como variável de tempo.

Resultados: 178 pacientes, 64(36\%) desenvolveram pelo menos uma lesão. As variáveis independentes para 0 risco de lesão foram: Braden<13(HR:10,6;|C95\%:2,5-43,7), histórico de Acidente Vascular Cerebral(HR:2,6; IC95\%:1,3-5,0), idade $>60$ anos(HR:2,0;|C95\%:1,2-3,5), tempo de Nada Pela via Oral(HR:1,06;|C95\%1,02-1,10) e dias de fisioterapia (HR:0,81;IC95\%:0,73-0,91).

Conclusão: Lesão por pressão foi evento incidente. Braden<13 pontos, história de acidente vascular cerebral, ser idoso e tempo de nada por via oral foram fatores de risco independente para lesão por pressão. Os dias de exposição à fisioterapia foram protetores. Esses achados corroboram que se monitore a incidência de lesão por pressão e estabeleça medidas protetoras embasadas em indicadores locais.

Palavras-chave: Lesão por pressão. Cuidados críticos. Unidades de terapia intensiva.

\section{RESUMEN}

Objetivo: Evaluar la incidencia y factores asociados con la lesión por presión en pacientes de un Centro de Terapia Intensiva (incluyendo varias Unidades de Terapia Intensiva) de un hospital universitario en el sur de Brasil.

Método: Cohorte que siguió variables clínicas y terapéuticas en un Centro de Terapia Intensiva. Se aplicó la regresión múltiple de Cox, en que se estableció como una variable de tiempo el número de días hasta la primera lesión por presión.

Resultados: 178 pacientes, 64(36\%) desarrollaron al menos una lesión por presión. Braden <13 (HR: 10.6; IC 95\%: 2.5-43.7), historia de accidente cerebrovascular (HR: 2.6; IC 95\%: 1.3-5.0), edad> 60 años (HR: 2.0; IC 95\%: 1.2-3.5), tiempo de nada por la boca (HR: 1.06; IC 95\% 1.02-1.10) y tiempo de fisioterapia (HR:0,81; IC del 95\%: 0,73 a 0,91).

Conclusión: La lesión por presión fue un evento incidente. Braden $<13$, accidente cerebrovascular previo, edad avanzada y tiempo de nada por la boca fueron factores de riesgo independientes para la lesión por presión. Los días de exposición a la fisioterapia fueron protectores. Estos hallazgos corroboran para monitorear la frecuencia de lesión por presión y establecer medidas de protección basadas en indicadores locales.

Palabras clave: Úlcera por presión. Cuidados críticos. Unidades de cuidados intensivos. 


\section{口INTRODUCTION}

Pressure wounds (PW) are dreaded injuries due to their potential of provoking discomfort ${ }^{(1)}$ and producing complications. In many health care settings throughout the world, their incidence and prevalence remain high. In patients hospitalized in Intensive Care Units (ICUs), the incidence of this type of event varies greatly (from 11.2 to 52.9\%), which can be explained by the fact that patients have different clinical profiles and different methodologies are used in the studies about the theme ${ }^{(2-4)}$.

There is no consensus in literature about PW associated factors, especially in ICU patients. After adopting many different designs, and not always employing a statistic capable of isolating the independent effect of each variable, literature shows some factors that can be associated to PW: (1) the impossibility of noticing or communicating pressure discomfort ${ }^{(5-7) ;}$; (2) the use of devices that can provoke wounds in the skin and its adjacent tissues, such as tubes, catheters, and others ${ }^{(8-9)} ;(3)$ malnutrition ${ }^{(10)} ;(4)$ advanced age ${ }^{(10) ;}$; (5) the inability to move in the bed or chair(11); (6) humidity, friction, and shear ${ }^{(12) ;}$; (7) hemodynamic instability ${ }^{(7)}$; and (8) longer hospitalization periods ${ }^{(13)}$.

Critical patients, therefore, are especially under the risk of PWs, since they present many of the factors mentioned ${ }^{(9)}$. Furthermore, the support therapies implemented during the treatment of critical patients would contribute for PWs to appear. The hospitalization in the ICU exposes the patients to invasive procedures, handling from the team, permanence in bed, and immobility, making them, therefore, more susceptible to PWs ${ }^{(14-15)}$. Although this problem is frequent, there are few studies either in national or international settings about PWs in, specifically, critical patients.

Getting to know the severity of the issue and the specific characteristics of a certain population is one of the stages of a situational diagnoses, which precedes the planning of preventive actions and treatment ${ }^{(15)}$. To this end, monitoring the cases of PW by determining their indexes and stratifying them according to the clinical and epidemiological profile of the patients become paramount actions, especially in health institutions that are engaged in the culture of patient safety ${ }^{(16)}$. The monitoring of the incidence and prevalence of PWs, seen as indicators of the quality of assistance, allows one to estimate up to what point different disciplines of care are adopting effective strategies to control them, and also for the identification of changes in the profile of users attended, since intrinsic conditions are important determinants of the outcome. All of the above are justifications of this research.
As a result, this study aimed at evaluating the incidence and the factors associated to PWs in patients of a Brazilian clinical and surgical Intensive Care Center (ICC).

\section{$\square$ METHOD}

This study derives from a prospective cohort designed to evaluate evacuation disorders (constipation and diarrhea) in adults from one Brazilian clinical and surgical high-complexity ICC (a center formed by three ICUs). The study included adults (age $>18$ years old) hospitalized for the first time in the ICC for at least 72 hours, free from evacuation disorders as they were admitted to the ICC, which had not undergone enemas or any other surgical preparations, who had no ostomies (colostomies or ileostomies), or who remained in the ICU post-anesthesia recovery room before being transferred to a general ICU. This cohort, therefore, was nested within the original cohort, maintaining the same eligibility criteria, except for the inclusion of 21 patients: 11 which had not been included in the original cohort because they stayed less than 72 hours in the ICU, while other 10 were monitored for longer than the time frame chosen for the original cohort. In the original cohort, the sample calculation included 157 patients, a number which increased to 178 patients after the adequate additions.

Prospective data collection took place from November 2015 to October 2016. The patients were accompanied prospectively from their admission to their discharge from the ICC, with regards to: biological characteristics (age, skin color, sex, origins), previous medical history (chronic and acute diseases, previous surgeries), current medical history (reason for ICU admission, vital signs, presence of infection, and other adverse events), severity scales (APACHE II Acute Physiology And Chronic Health Evaluation II, SOFA - Sequential Organ Failure Assessment), therapies and interventions implemented at the ICC (surgeries, diagnostic procedures, antibiotic use, vasoactive drugs, sedation, analgesia, mechanical ventilation, hemodialysis, monitoring, enteral nutrition, physical therapy, care, devices) and clinical conditions presented during ICC hospitalization (progress, adverse events, PWs). Each day, a team of previously trained nurses visited the patients and obtained data from their records and from the health care team. The skin of the patients was not examined by the research team; the data, as well as the data on the changes of decubitus, movement and leaving the bed, use of diapers, presence of PWs, were evaluated in the records of the patients retrospectively from November 2016 to May 2017. 
Starting on the first day of study of the original cohort, the first 10 patients who were hospitalized in the ICU were included. They were monitored until they were discharged from the ICU or died. Only after a patient left the study, another was admitted as a participant. As a result, there was always a maximum of 10 patients being monitored. When more than one patient was eligible to enter the study, a random selection was carried using the smartphone application IGerar ${ }^{\oplus}$. In the period of the study,2,651 patients were hospitalized in the ICC, 352 were evaluated for possible inclusion in the study, and 195 were not in accordance with the inclusion criteria.

Data were typed in and analyzed using the software Statistical Package for the Social Sciences (SPSS), version 20.0. At first, a descriptive analysis was carried out, and the results were expressed by mean \pm standard deviation (SD), median (P50) and percentiles (P25 - P75), or through absolute and relative frequencies, according to the characteristics of the variables. The distribution of variables was tested using the Shapiro-Wilk test. Later, a univariate analysis was carried out using parametric tests (Student's T test) and non-parametric (Mann-Whitney's, Chi-squared), followed by a univariate Cox's Regression. Time, expressed in days, until the first PW, was the variable for time adjustment in Cox's regression. Variables whose p-value was $\leq 0.20$ in the univariate Cox's Regression were included in a multivariate Cox's Regression model, using the function "enter". $P \leq 0.20$ meant that the probability for the findings of the univariate analysis to happen differently than the demonstration in the analysis is $20 \%$. It is, therefore, a highly inclusive value, more than including only variables whose value was $p<0.5$. Removing the variables in the modeling stage was done considering the one that had the highest $p$-value, until only those whose $p$-value was < 0.05 were left in the study. The model was adjusted using an omnibus test. Variables indicated in the literature review as PW risk factors were inserted in the modeling stage, although, in the univariate analysis, the p-value was $>0.20$.

\section{Ethical concerns}

The ethical and methodological aspects of the study were approved by the Research Ethics Committee (number of the Certificate of Submission to Ethical Appreciation: 47903015.2.1001.5327). The Ethics Committee exempted this work from requiring a Free and Informed Consent Form. The researchers and research assistants signed a Form of Responsible Data Usage.

\section{RESULTS}

The patients ( $n=187$ ) were $57.8 \pm 15.5$ years old, mostly male $(55.1 \%)$, from the emergency service of the hospital (47.2\%), admitted in the ICC due to recovery needs or hospital emergency (24.7\%) and sepsis (23\%). Only $7.9 \%$ of patients self-declared their skin color as black. The most prevalent previous diseases were systemic arterial hypertension, HAS (50.6\%); diabetes mellitus, DM (26.4\%); cancer (19.7\%); chronic renal failure, CRF (14.6\%); and cerebrovascular accident, CA (10.7\%), as detailed in Table 1.

At the moment of admission into the ICC, 16 patients already had at least one PW, which was either acquired in their community or in another unit of the hospital; 11 of them developed other PWs during ICC hospitalization.

Among the 178 patients of the study, 64 developed at least one PW during ICU hospitalization, resulting in a $36 \%$ incidence of PWs. The incidence had a density of $0.46 \mathrm{PW} / 1000$ days of hospitalization. In patients who developed PWs, the median number of hospitalization days in the ICU previous to the clinical diagnosis of a PW was 3 (P25:2; P75:6) days.

Figure 1 , whose data were collected at 14 days of monitoring, show that more than $40 \%$ of the PWs take place up to the 2 nd day of hospitalization in the ICU, and that most PWs (60.3\%) happen early (up to the 3rd day of ICU hospitalization).

In the 64 patients who presented PWs, 102 PWs were found. 38 patients presented a single wound, while 18 presented 2 wounds, 7 presented 3 wounds, and 1 patient presented 4. There were different levels of PW progress: Stage 1 (42.2\%); Stage 2 (35.3\%); and Profound Tissue Wound (17.6\%). Anatomically, the most affected regions were the sacrum region (47.2\%); the calcaneus (29.5\%), the gluteus (8.8\%), and the scapula (4.9\%). A lower number of wounds (2.9\% for each) was found in the elbows, trochanters, malleolus, and a single patient developed a wound in the occipital region (0.9\%).

The univariate analysis showed some differences between the groups of patients who already showed PWs at the admission to the ICC. Patients with PWs were older $(p=0.007)$, presenting higher APACHE II (Acute Physiology and Chronic Health Evaluation) ( $p=0.003$ ) and SOFA (Sequential Organ Failure Assessment) ( $p=0.008$ ) levels. Most of them originated from the emergency room, and least from other areas, such as the surgical ward and hospitalization unit $(p=0.03)$. Their hospitalization in the ICC took place for different reasons, in most cases due to sepsis and respiratory problems ( $p=$ 0.007). Regarding previous diseases, there was no difference 
Table 1 - Characteristics of the total of patients of the sample at the moment of their admission to the ICC, comparing those with and without PWs. Data expressed as mean \pm standard deviation or median (P25-75), absolute numbers (relative numbers), according to the characteristics of the variables. Porto Alegre, RS, Brazil, 2018

\begin{tabular}{|c|c|c|c|c|}
\hline & All $(n=178)$ & With PWs (n=64) & $\begin{array}{l}\text { Without PWs } \\
(n=114)\end{array}$ & $\mathbf{p}$ \\
\hline Male & $98(55.1)$ & $38(30.9)$ & $60(61.2)$ & 0.47 \\
\hline Age, years & $57.8 \pm 15.5$ & $62 \pm 14.8$ & $55.5 \pm 15.4$ & 0.007 \\
\hline APACHE II & $21.5 \pm 8.4$ & $24.1 \pm 7.8$ & $19.1 \pm 8.2$ & 0.003 \\
\hline SOFA (1ºdia) & $6(4-10)$ & $7.5(5-11)$ & $6(3-9)$ & 0.008 \\
\hline Origin & & & & 0.032 \\
\hline Emergency service & $84(47.2)$ & $33(51.6)$ & $51(44.7)$ & \\
\hline Surgical Unit & $45(25.3)$ & $8(12.5)$ & $37(32.5)$ & \\
\hline Hospitalization Unit & $39(21.9)$ & $18(12.5)$ & $21(18.4)$ & \\
\hline External & $8(4.5)$ & $3(4.7)$ & $5(4.4)$ & \\
\hline Reason for ICC hospitalization & & & & 0.007 \\
\hline Postoperative period & $44(24.7)$ & $9(14.1)$ & $35(30.7)$ & \\
\hline Sepsis & $41(23)$ & $24(37.5)$ & $17(14.9)$ & \\
\hline Neurological & $31(17.4)$ & $11(17.2)$ & $20(17.2)$ & \\
\hline Respiratory & $31(17.4)$ & $13(20.3)$ & $18(15.8)$ & \\
\hline Cardiological & $13(7.3)$ & $5(7.8)$ & $8(7)$ & \\
\hline Gastroenterological & $5(2.8)$ & $1(1.6)$ & $4(3.5)$ & \\
\hline Others & $13(7.3)$ & $1(1.6)$ & $12(10.5)$ & \\
\hline \multicolumn{5}{|l|}{ Previous diseases } \\
\hline $\mathrm{SAH}$ & $90(50.6)$ & $35(54.7)$ & $55(48.2)$ & 0.504 \\
\hline $\mathrm{DM}$ & $47(26.4)$ & $18(28.1)$ & $29(25.4)$ & 0.831 \\
\hline Cancer & $35(19.7)$ & $16(25)$ & $19(16.7)$ & 0.252 \\
\hline CRF & $26(14.6)$ & $13(20.3)$ & $13(11.4)$ & 0.163 \\
\hline CA & $19(10.7)$ & $12(18.8)$ & $7(6.1)$ & 0.018 \\
\hline COLD & $17(9.6)$ & $6(9.4)$ & $11(9.6)$ & 1.000 \\
\hline IC & $15(8.4)$ & $6(9.4)$ & $9(7.9)$ & 0.952 \\
\hline CCF & $14(7.9)$ & $6(9.4)$ & $8(7)$ & 0.787 \\
\hline Skin color (self-declared) & & & & 1.000 \\
\hline White & $164(92.1)$ & $59(36)$ & $105(64)$ & \\
\hline Black & $14(7.9)$ & $5(35.7)$ & $9(64.3)$ & \\
\hline
\end{tabular}

Source: Research data, 2018.

Caption: APACHE II - Acute Physiologic Chronic Health Evaluation II; SOFA - Sepsis-related Organ Failure Assessment; ICC - Intensive Care Center; SAH - systemic arterial hypertension; DM - Diabetes Mellitus; COLD - chronic obstructive lung disease; CRF - chronic renal failure; CHF - congestive heart failure; IC - ischemic cardiopathy; - cerebrovascular accident. 


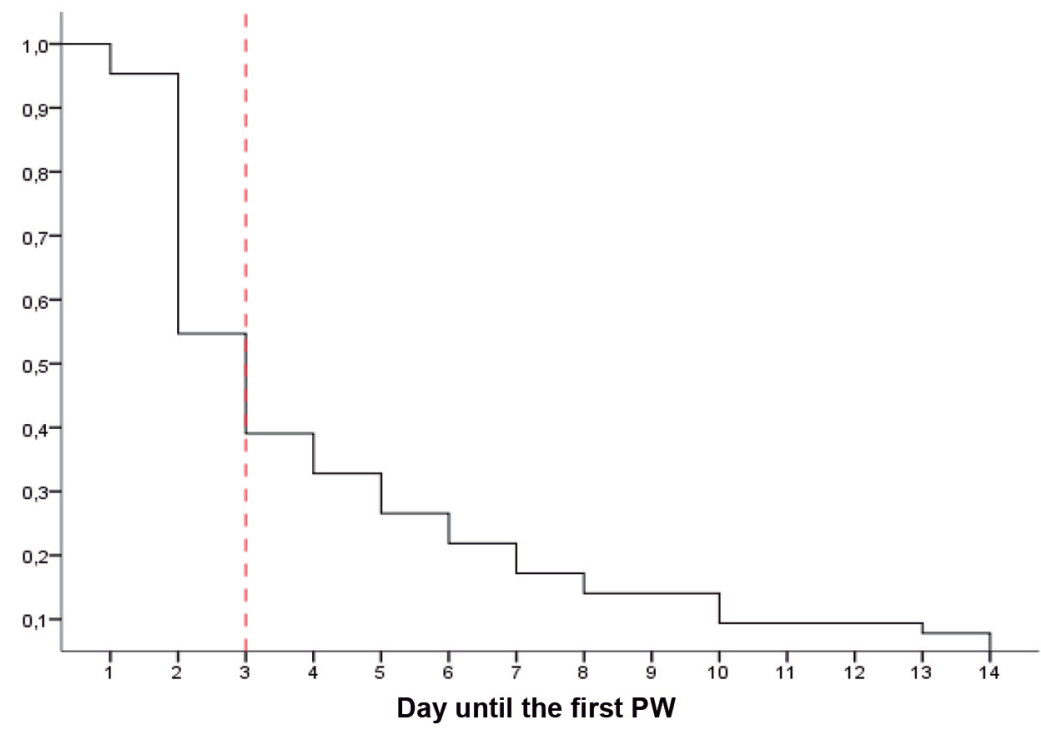

\begin{tabular}{|c|c|c|c|c|c|c|c|c|c|c|c|c|c|c|}
\hline $\mathrm{N}$ & 3 & 26 & 10 & 4 & 4 & 3 & 3 & 2 & 0 & 3 & 0 & 0 & 1 & 2 \\
\hline$\%$ & 4.7 & 40.6 & 15.6 & 6.3 & 6.3 & 4.7 & 4.7 & 3.1 & 0 & 4.7 & 0 & 0 & 1.6 & 3.1 \\
\hline
\end{tabular}

Figure 1 - Time in days until the first PW. Porto Alegre, RS, Brazil, 2018

Source: Research data, 2018.

Kaplan-Meier

between the groups, except for the frequency of CAs, which was higher in the group with PWs ( $p=0.018)$ (Table 1).

Throughout the days of hospitalization in the ICU, the patients were submitted to different support therapies. Invasive mechanical ventilation (IMV) (78\%), renal replacement therapy (RRT) (22.5\%), vasoactive drugs (61.2\%), and sedation (75.8\%) (Table 2). It is important to note that, in this sample of patients, there was no case of decubitus change into a prone position.

The univariate analysis showed that patients with PWs used more IMV ( $p=0.014)$, renal replacement therapy - RRT $(p=0.008)$, vasopressor drugs $(p=0.000)$, sedation $(p=$ $0.001)$, and neuromuscular blockers ( $p=0.01$ ); their mean arterial pressure (MAP) showed a lower mean $(p=0.045)$ and the time spent receiving nothing by mouth $(p=0.011)$ was greater, meaning the length of time they received diets not through the mouth but through nasoenteric tubes was higher than that of patients with no PWs $(p=0.000)$. There were more diaper users until the 3 rd day of admission in the ICC $(p=0.011)$, they were submitted to more decubitus changes $(p=0.000)$ and showed more changes in their neurological state (Rass -5 or Glasgow $\leq 6)(p=0.000)$. The subscale "Mobility" of the Braden scale was evaluated up to the 3rd day, and patients with PWs were classified as "Completely immobile" or "Very limited" ( $p=0.023)$. Furthermore, the most common values for the Braden scale were $<13$ ( $p$ $=0.000)$ and most presented previous PWs $(p=0.001)$. The patients who developed PWs spent more time in the ICC ( $p$ $=0.000)$ and had a higher mortality rate $(p=0.000)$ (Table 2$)$.

Figure 2 shows the risk of death, adjusted for the days of ICC hospitalization in the groups of patients with and without PWs, represented, respectively, by red and green lines. The risk of death was higher for patients with no PWs (Log-Rank test: 18.704; $p=0.000$ ), suggesting that patients who did not develop PWs died before they could be formed.

Using a multiple regression, the following independent variables were found for PW risk: (a) score in Braden scale $<13$ $<13$ (HR: 10.6; C195\%: 2.5 - 43.7), (b) having had a CA before admission into the ICC (HR: 2.6; C195\%: 1.3 - 5.0), (c) age > 60 years (HR: 2.0; C195\%: $1.2-3.5)$, and (d) mean hours in nothing by mouth (HR: 1.06; C195\% 1.02 - 1.10). Furthermore, for each day of physical therapy, the risk of PWs diminished (reduction of relative risk) in 19\% (HR: 0.81; C195\%: $0.73-0.91$ ). 
Table 2 - Therapies, medications, and clinical aspects observed throughout the days of ICC hospitalizations in the patients of the sample $(n=178)$, when comparing patients with PWs $(n=64)$ and those without $(n=114)$. Data expressed as mean \pm standard deviation or median (P25-75), absolute numbers (relative numbers), according to the characteristics of the variables. Porto Alegre, RS, Brazil, 2018

\begin{tabular}{|c|c|c|c|c|}
\hline & All $(n=178)$ & With PWs $(n=64)$ & $\begin{array}{l}\text { Without PWs } \\
(n=114)\end{array}$ & $\mathbf{p}$ \\
\hline MV & $139(78.1)$ & $57(89.1)$ & $82(71.9)$ & 0.014 \\
\hline MV time (days) & $2(1-4)$ & $2(2-4)$ & $1(1-4)$ & 0.052 \\
\hline HD & $40(22.5)$ & $22(34.4)$ & $18(15.8)$ & 0.008 \\
\hline HD time (hours) & $0(0-0)$ & $0(0-7.8)$ & $0(0-0)$ & 0.006 \\
\hline Vasopressor & $109(61.2)$ & $51(79.7)$ & $58(50.9)$ & 0.000 \\
\hline Vasopressor time (days) & $2(0-4)$ & $2(1-3)$ & $0(1-2)$ & 0.002 \\
\hline Sedation & $135(75.8)$ & $58(90.6)$ & $77(67.5)$ & 0.001 \\
\hline Sedation time (days) & $2(0-4)$ & $2(2-4)$ & $1(0-3.2)$ & 0.000 \\
\hline Neuromuscular blocker & $29(16.3)$ & $17(26.6)$ & $12(10.5)$ & 0.010 \\
\hline Antibiotics use & $148(83.1)$ & $58(90.6)$ & $90(78.9)$ & 0.074 \\
\hline MAP mean & $65.7 \pm 11.6$ & $63.5 \pm 12.4$ & $67 \pm 10$ & 0.045 \\
\hline Nothing by mouth time (hours) & $8(3.9-12)$ & $10.6(3.5-21.7)$ & $6.4(4-10)$ & 0.011 \\
\hline Predominant diet & & & & 0.000 \\
\hline Nothing by mouth & $75(44.4)$ & $31(49.2)$ & $44(41.5)$ & \\
\hline Ol & $44(26)$ & $4(6.3)$ & $40(37.7)$ & \\
\hline NET & $50(29.6)$ & $28(44.4)$ & $22(20.8)$ & \\
\hline Use of diapers up to the $3 \mathrm{rd}$ day & $82(46.1)$ & $34(53.1)$ & $48(42.1)$ & 0.011 \\
\hline Decubitus changes & $7(2-18.2)$ & $14(5.2-28)$ & $4.5(0-12.5)$ & 0.000 \\
\hline Motor physical therapy & $2(1-3)$ & $2(0-4.5)$ & $2(1-3)$ & 0.246 \\
\hline Neurological & & & & 0.000 \\
\hline Rass -5 ou Glasgow $<6$ & $68(83.1)$ & $39(60.9)$ & $29(25.4)$ & \\
\hline Mobility until the 3rd day & & & & 0.023 \\
\hline Immobile or very limited & $144(80.9)$ & $58(90.6)$ & $86(75.4)$ & \\
\hline Slightly limited or no limitation & $34(19.1)$ & $6(9.4)$ & $28(24.6)$ & \\
\hline Braden scale & & & & 0.000 \\
\hline Braden $\leq 13$ & $132(74.2)$ & $62(96.9)$ & $70(61.4)$ & \\
\hline Braden $>13$ & $46(25.8)$ & $2(3.1)$ & $44(38.6)$ & \\
\hline Previous PWs & $16(9)$ & $11(17.2)$ & $5(4.4)$ & 0.010 \\
\hline
\end{tabular}


Table 2 - Cont.

\begin{tabular}{lcccc} 
& All $(\mathbf{n = 1 7 8})$ & With PWs (n=64) & $\begin{array}{c}\text { Without PWs } \\
(\mathbf{n = 1 1 4})\end{array}$ \\
\hline $\begin{array}{l}\text { Outcomes } \\
\text { Days in the ICC } \\
\text { Death }\end{array}$ & $5(4-10)$ & $9(5-15)$ & $5(3-7.5)$ & 0.000 \\
\hline
\end{tabular}

Source: Research data, 2018.

Caption: MV - mechanical ventilation; HD - hemodialysis; ATB - antibiotics; MAP - mean arterial pressure; OI - Oral intake; NET - nasoenteric tube; RASS - Richmond Agitation-Sedation Scale.

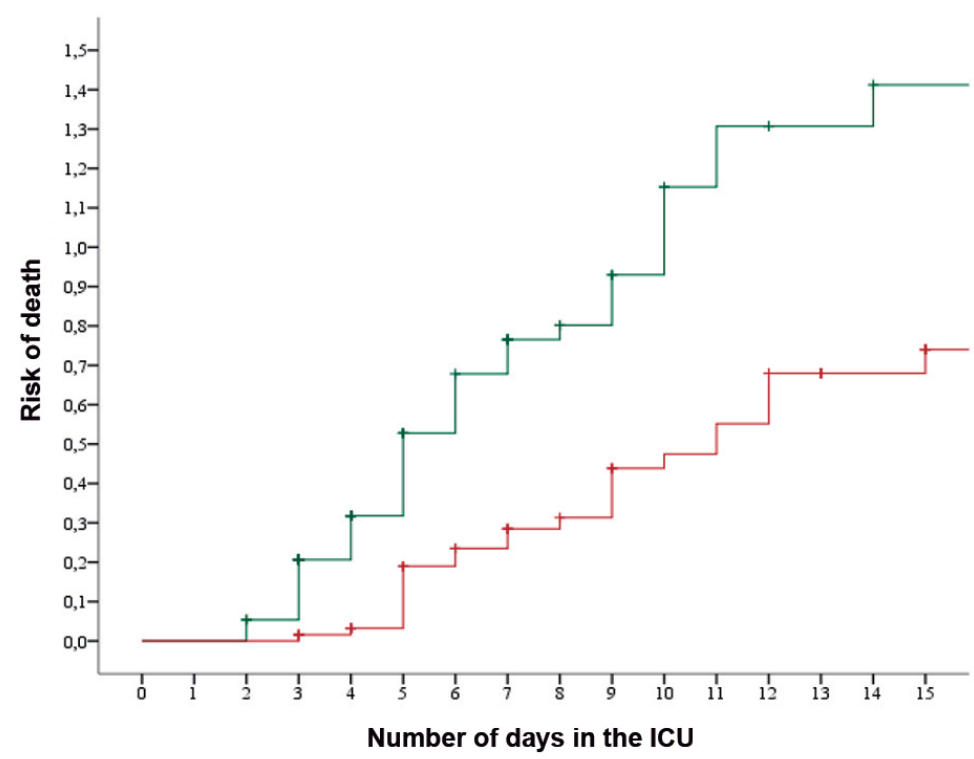

Figure 2 - Comparison of the risk of death, throughout the days of ICU hospitalization, between patients with PWs (continuous red line) and those without (continuous green line). Data collected in 15 days of ICU hospitalization. Porto Alegre, RS, Brazil, 2018

Source: Research data, 2018. __ patients with PW; _ patients with no PW.

Cox's regression was applied.

Table 3 - Variables associated to the risk of PWs in critical patients. Data expressed using Hazard Ratio values (gross and adjusted), with 95\% confidence intervals. Porto Alegre, RS, Brazil, 2018

\begin{tabular}{|c|c|c|c|c|}
\hline Variables & $\mathrm{HR}(\mathrm{Cl} 95 \%)$ & $\mathbf{p}$ & $\begin{array}{l}\text { Adjusted HR } \\
\text { (CI 95\%) }\end{array}$ & $\mathbf{p}$ \\
\hline Braden $\leq 13$ & $9.21(2.24-37.80)$ & 0.002 & $10.6(2.5-43.7)$ & 0.001 \\
\hline Previous CA & $1.75(0.93-3.31)$ & 0.082 & $2.6(1.3-5.0)$ & 0.006 \\
\hline Age $>60$ years & $0.59(0.35-1.01)$ & 0.058 & $2.01(1.2-3.5)$ & 0.013 \\
\hline Mean hours in nothing by mouth & $1.09(1.05-1.12)$ & 0.000 & $1.06(1.02-1.10)$ & 0.001 \\
\hline Days of physical therapy & $0.89(0.82-0.96)$ & 0.003 & $0.81(0.73-0.91)$ & 0.000 \\
\hline
\end{tabular}

Source: Research data, 2018.

Caption: CA: cerebrovascular accident.

Cox's multivariate regression was applied. 


\section{DISCUSSION}

This study found that the PW is an event with incidence among critical patients, since more than $1 / 3$ of patients in the sample had at least one PW. In univariate analyses, variables related to the clinical state of patients and their treatment were pointed out as presenting risk for PWs. However, as opposed to some of our presuppositions and of findings from previous studies, after an adjustment for confusing factors was made, the only variables associated independently to the risk to this outcome were Braden scale $<13$, previous CA, age $>60$ years, and the mean hours on nothing by mouth. Also, independently, the number of days of physical therapy was found to be protective.

The incidence rate found in this study was nine times higher than the one shown in the PW indicator measures by the institution that was the setting of this study (4.9\%), in the same period and in the same location (unpublished data, provided by the management of the ICC of the hospital that was the setting of this study). The fact that the institutional records does not include stage I PWs, which were $42 \%$ of the PWs in this study, could partly justify this difference. Although prevalent, stage I PWs are harder to diagnose, and, thus, are not included in the counting of the indicators of many services which measure PW rates ${ }^{(17-19)}$. Furthermore, PW undernotification on the part of health care teams is an issue. A cross-sectional study analyzed retrospective data and compared the rate of notifications of PWs (institutional indicator) to the notes about PWs registered in the progress (records) of the patients from hospitalization units from the same hospital that was the setting of this study. The evaluation only considered stage II or higher PWs, and the authors found that, while the PW rate notified was 3\%, the notes in the records found an incidence of $10 \%{ }^{(19)}$. Similarly, undernotification was mentioned in another cross-sectional study carried out in the general ICU of a university hospital in São Paulo. For one month, PW notifications and the notes made by nurses in medical records were monitored. The authors reported that, among the nine patients with PWs, only three were notified in the information system that generates data to inform the PW indicator.

Researches which tried to identify the incidence of PWs on intensive care showed heterogeneous results; that can be explained by the difference in the profile of patients and in the methodologies used ${ }^{(5)}$. A study followed patients for three months in semi-intensive and intensive hospitalization units of a university hospital of São Paulo. The worldwide incidence rate of PWs was 39.8\%. Specifically in the ICU, the rate was $41 \%$. When the authors calculated the rates, excluding patients with stage I PWs, with the justification that these tend to be undernotified, the incidence of PWs in the ICU diminished in half $(20.5 \%)^{(4)}$. Another research carried out in a hospital in the south of Brazil sought to identify the incidence of PWs in an ICU. Only 22 PWs were found in 21,227 patients. However, the authors themselves state that this low incidence is very different than the results recorded in literature, and that it is possible that this event was undernotified. The undernotification was related to the turnover of professionals, to problems in communication, and to the lack of knowledge about the routine of the institution ${ }^{(3)}$.

Part of the nursing literature deals with PWs as adverse events related to assistance ${ }^{(1-2)}$. This type of wound is classified as a "preventable event", and it has been stated that "... it is important to adopt preventive measures, such as decubitus changes, protectors for prominent bones, skin inspection and protection, in addition to identifying the clients under the risk of developing the ulcer"(1-2). However, in critically ill patients, other variables related to the characteristics of the patients and their treatments must be considered in addition to nursing care, in order to attempt to explain the presence of PW.

Studies suggest that an advanced age, being female, and being white are intrinsic factors in the development of PW. Among these factors, in this study, only the age $>60$ was found to be an independent risk predictor for PWs. As age increases, the skin becomes drier, due to the diminution of sebaceous and sweat glands, leading to diminished vascularization, texture, and elasticity, and muscle atrophy, which makes bone structures more prominent and leads tissue trauma to happen faster ${ }^{(7)}$. The association between sex and PW is not clear. In this study, a univariate preliminary analysis showed that men were more likely to develop PWs, similarly to the results of other studies ${ }^{(4)}$. With regard to skin color, it is known that white skin is less resistant to external aggression from humidity and friction, when compared to black skin ${ }^{(5)}$. It stands out that, in the sample analyzed here, the number of patients who self-declared as non-white (black) was very small.

No studies were found which, like this one, specifically identified nothing by mouth time as a risk for PWs. However, the clinical situation of ICU patients is known to frequently prevent nutritional therapy, and intestinal motility problems secondary to postoperative ileus are common, as well as gastric or intestinal stasis, hypoperfusion, sepsis, trauma, shock, and multiple organ malfunction ${ }^{(18)}$. Furthermore, fasting is frequent, especially among postoperative patients, which contributes to worsen the nutritional state of previously malnourished patients, prolonging hospitalization times 
and increasing the chance of hospital complications, such as PWs ${ }^{(10)}$. Therefore, the nutritional started to be considered as a domain of evaluation scales for PW, such as the Braden scale ${ }^{(10)}$.

Noncommunicable chronic diseases are considered to be PW predictors in many studies. The CA is more prevalent in patients with PWs ${ }^{(10,16)}$. In this study, the CA which took place before admission in the ICC was found to be an independent risk factor for PW development.

In the sample studied, exposure to physical therapy was found to be a protective factor against PWs. The capacity of moving and decubitus changes were protective factors in a study whose methodology was similar to ours ${ }^{(5)}$. Moving the limbs, even passively, improves the blood flow, in a way that increases the offer of oxygen to the tissues and prevents the appearance of lesions and contractures ${ }^{(6-7)}$.

Furthermore, Cox's regression was used, making it possible to consider the time of exposure as an important adjustment factor for the outcome being discussed. In addition, this study allowed the prospective monitoring of variables related to the clinic and to therapies for life support (medication, mechanical ventilation, nutritional and renal replacement therapies, etc.), all of which were monitored with regard to dosage and time of use, information not included in the Chinese study. Therefore, in spite of the low number of subjects in this study, the model found seems to explain better the phenomenon, for this medium.

The scarcity and inadequacy of the record in medical records compromises the continuity of the planning of care in its different stages, the assistance planning of the multiprofessional team, and patient safety, and can be a limitation of this study.

\section{$\square$ CONCLUSION}

The incidence of PWs was high in the sample studied. The data of PW incidence in the institution under study showed that there was undernotification. In addition to classic factors, such as Braden scale score $<13$, other variables were found as being risk variables for PW in the days of ICU hospitalization: previous CA, age $>60$ years old, and mean of hours in nothing by mouth. It was also found that, independently, the number of days of physical therapy was found to be protective.

The robust methodology and the data analysis provide important information to guide the clinical practice in the establishment of protocols and assistance routines, since it was found that most PWs happen early and are associated to specific characteristics.

\section{REFERENCES}

1. Jackson D, DurrantL, Bishop E, Walthall H, Betteridge R, Gardner S, et al. Pain associated with pressure injury: a qualitative study of community-based, home-dwelling individuals. J Adv Nurs. 2017;73(12):3061-9. doi: https://doi.org/10.1111/jan.13370

2. CampaniliTCG,SantosVLCG, Strazzieri-Pulido KC, ThomazPBM, NogueiraPC. Incidence of pressure ulcers in cardiopulmonary intensive care unit patients. Rev Esc Enferm USP. 2015;49(spe):7-14. doi: https://doi.org/10.1590/S0080-623420150000700002

3. Alderden J, Rondinelli J, Pepper G, Cummins M, Whitney JA. Risk factors for pressure injuries among critical care patients: a systematic review. Int J Nurs Stud 2017;71:97-114. doi: https://doi.org/10.1016/j.jnurstu.2017.03.012

4. Borghardt AT, Prado TN, Bicudo SDS, Castro DS, Bringuente MEO. Pressure ulcers in critically ill patients: incidence and associated factors. Rev Bras Enferm. 2016;69(3):460-7. doi: https://doi.org/10.1590/0034-7167.2016690307i

5. Otto C, Schumacher B, Wiese L, Ferro C, Rodrigues R. Fatores de risco para 0 desenvolvimento de lesão por pressão em pacientes críticos. Enferm Foco. 2019;10(1):7-11. doi:https://doi.org/10.21675/2357-707X.2019.v10.n1.1323

6. WoundSource (US) [Internet]. Atlantic Beach (FL); (2016-2020 [cited 2020 Jan 10]. National Pressure Ulcer Advisory Panel (NPUAP) announces a change in terminology from pressure injury and updates the stages of pressure injury; [about 1 screen]. Available from: https://www.woundsource.com/blog/national-pressureulcer-advisory-panel-npuap-announces-change-in-terminology-pressure-ulcer

7. Loudet Cl, Marchena MC, Maradeo MR, Fernández SL, Romero MV, Valenzuela $\mathrm{GE}$, et al. Reducing pressure ulcers in patients with prolonged acute mechanical ventilation: a quasi-experimental study. Rev Bras Ter Intensiva. 2017;29(1):39-46. doi: https://doi.org/10.5935/0103-507x.20170007

8. Cavalcanti E0, Kamada I. Medical-device-related pressure injury on adults: an integrative review. Texto Contexto Enferm. 2020;29:e20180371. doi: https://doi. org/10.1590/1980-265x-tce-2018-0371

9. Galetto SGS, Nascimento ERP, Hermida PMV, Malfussi LBH. Medical device-related pressure injuries: an integrative literature review. Rev Bras Enferm. 2019;72(2):50512. doi: https://doi.org/10.1590/0034-7167-2018-0530

10. Nuss S, Medeiros K, Alonso M, Gomes N, Fumian L. Importância da abordagem multidisciplinar no tratamento da úlcera por pressão em pacientes com sequelas incapacitantes: relato de caso Sara. Acta Biomed Bras. 2015 [cited 2020 Jjan 10];6(1):78-83. Available from: https://www.actabiomedica.com.br/index. php/acta/article/view/102/0

11. McInnes E, Jammali-Blasi A, Bell-Syer SEM, Dumville JC, Middleton V, Cullum N. Support surfaces for pressure ulcer prevention. Cochrane Database Syst Rev. 2015;9(5):CD001735. doi: https://doi.org/10.1002/14651858.CD001735.pub5

12. Tayyib N, Coyer F, Lewis P. Saudi Arabian adult intensive care unit pressure ulcer incidence and risk factors: a prospective cohort study. Int Wound J. 2016. 2016;13(5):912-9. doi: https://doi.org/10.1111/iwj.12406

13. Becker D, Tozo TC, Batista SS, Mattos AL, Silva MCB, Rigon S, et al. Pressure ulcers in ICU patients: incidence and clinical and epidemiological features: a multicenter study in Southern Brazil. Intensive Crit Care Nurs 2017;42:55-61. doi: https://doi. org/10.1016/j.iccn.2017.03.009

14. Deng X, Yu T, Hu A. Predicting the risk for hospital-acquired pressure ulcers in critical care patients. Crit Care Nurse. 2017;37(4):e1-11. doi: https://doi. org/10.4037/ccn2017548

15. Chacon JMF, Blanes L, Borba LG, Rocha LRM, Ferreira LM. Direct variable cost of the topical treatment of stages III and IV pressure injuries incurred in a public university hospital. JTissue Viability 2017;26(2):108-12. doi: https://doi. org/10.1016/j.jtv.2016.12.003 
16. Santiago THR, Turrini RNT. Organizational culture and climate for patient safety in Intensive Care Units. Rev Esc Enferm USP. 2015;49(spe):123-30. doi: https:// doi.org/10.1590/50080-623420150000700018

17. Mehaffey JH, Politano AD, Bhamidipati CM, Tracci MC, Cherry KJ, Kern JA, et al. Decubitus ulcers in patients undergoing vascular operations do not influence mortality but affect resource utilization. Surgery. 2017;161(6):1720-7. doi: https://doi.org/10.1016/j.surg.2017.02.002

\section{- Authorship contributions:}

Alexandra Nogueira Mello Lopes: creation, data selection, formal analysis, investigation, methodology, supervision, validation, writing of the original draft, revision, and editing.

Erica Batassini: creation, data selection, formal analysis, investigation, methodology, and supervision.

Mariur Gomes Beghetto: creation, data selection, formal analysis, investigation, methodology, supervision, validation, writing of the original draft, revision, and editing.

\section{- Corresponding author:}

Alexandra Nogueira Mello Lopes

E-mail:anlopes@hcpa.edu.br
18. FulbrookP, Anderson A. Pressure injury risk assessment in intensive care: comparison of inter-rater reliability of the COMHON (Conscious level, Mobility, Haemodynamics, Oxygenation, Nutrition) Index with three scales. J Adv Nurs. 2016;72(3):680-92. doi: https://doi.org/10.1111/jan.12825

19. Santos CT, Oliveira MC, Pereira AGDS, Suzuki LM, Lucena ADF. Pressure ulcer care quality indicator: analysis of medical records and incident report. Rev Gauch Enferm. 2013;34(1):111-8. doi: https://doi.org/10.1590/S1983-14472013000100014

\section{Associate editor:}

